\title{
Effect COVID 19 in the Mental Health of the Population During the Pandemic: A Mini Review
}

\author{
Valbona Uka*
}

Kosovo

ISSN: 2639-0612

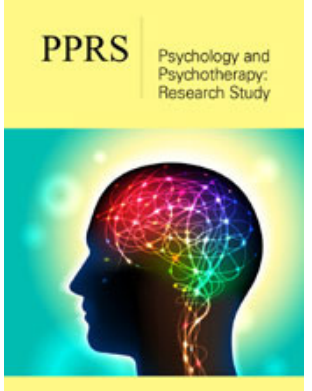

*Corresponding author: Valbona Uka, Kosovo

Submission: 皆 October 25, 2021

Published: 㭗 November 05, 2021

Volume 5 - Issue 2

How to cite this article: Valbona Uka. Effect COVID 19 in the Mental Health of the Population During the Pandemic: A Mini Review. Psychol Psychother Res Stud. 5(2). PPRS. 000607. 2021. DOI: 10.31031/PPRS.2021.05.000607

Copyright@ Valbona Uka, This article is distributed under the terms of the Creative Commons Attribution 4.0 International License, which permits unrestricted use and redistribution provided that the original author and source are credited.

\begin{abstract}
The first case of COVID-19 in Kosovo appeared on March 13, 2020, and continues to this day. This pandemic situation has been going on for 1 year and 7 months, the infection curve with Covid-19 is changing in different time periods, one period the virus is very aggressive while the next period the infection curve is decreasing, this change of the infection curve has confronted the population with news about the coronavirus (COVID-19) occupying the front pages of newspapers, and is continuing to cause anxiety, fear, insecurity even though the virus is weaker continues to infect us and put our lives in danger. This pandemic affects our health and reminds us how important it is to take care of our mental health in addition to our physical health.
\end{abstract}

Keywords: Covid-19; Kosovar population; Effect; Mental health

\section{Introduction}

The recent Covid-19 pandemic has had a significant effect on the mental health of the Kosovar population. Local research has mainly focused on stress, anxiety, depression, and burnout and these studies have highlighted the impact of the Covid-19 pandemic, specifying that fear of COVID-19 has a positive correlation with stress, anxiety, and depression in citizens of Kosovo, so there is a positive correlation between DASS21 and COVID-19. The correlation analysis results that stress, anxiety, and depression have a high positive correlation, but above all, stress has the highest correlation continuing later with anxiety and depression. From this, we conclude that for the Kosovar population the more they are afraid of COVID-19, the more the level of stress, anxiety, and depression will increase [1].

However, researchers have also studied the demographic characteristics of the population and the differences in the level of stress and anxiety. According to the results, we conclude that there are differences in the level of anxiety and that men exhibit a higher level of anxiety than women. In the level of stress, although the differences are not significant, there are differences in the average where men still exhibit a higher level of anxiety and stress higher than women. This result of ours is not consistent with other research like where women have actually shown higher levels of stress and anxiety as much fear of COVID-19. [2].

The COVID-19 pandemic has undoubtedly affected health workers who are in the front line against COVID-19, and have faced overwork at work, high stress, pressure, fear, fatigue, insecurity; they have realized the danger to become infected and the pressure to provide quality health services during the pandemic. Our findings show that the spread of COVID-19 in health workers has shown an intense workload, the need to continue living, the provision of health services for patients with the virus, shows that there is a statistically significant change in the level of chronic stress in health workers during the pandemic. Based on the correlation analysis the result shows that there is a positive and quite significant relationship between chronic stress and burn syndrome in health workers during the pandemic. Identifying and preventing burns through psychological services would be a necessary help for health care workers during the pandemic period [3-6]. 


\section{Conclusion}

The COVID-19 pandemic, according to research, has had a profound impact on the physical health and well-being of the population, beyond the impact on physical health, the ongoing uncertainty about the pandemic, and the dramatic behavioral changes required by social distance efforts, have a negative and profound effect on mental health.

Based on some research in Kosovo, we conclude that:

1. The more one is afraid of COVID-19, the more the level of anxiety, stress, and depression will increase [7-9].

2. Ore males have shown a higher level of anxiety and that urban areas are more affected by the higher level of anxiety than rural areas [10].

3. Age 50 shows the highest average anxiety.

4. The highest average of stress is displayed by persons aged 18-30 years.

5. Health workers have shown an intense workload and chronic stress including the risk of burn syndrome after a period of time.

These research results should be taken into account and the recommendations given should be implemented, strategic planning for the protection of mental health should be done by the Ministry of Health, the establishment of a multidisciplinary team for professional intervention during the pandemic, and the provision of psycho-social services during and by COVID-19 [11,12].

\section{References}

1. Uka V, Retkoceri G, Beka D, Karameta M (2021) The association between fear of COVID-19 and the level of stress, anxiety and depression. International Journal of Acta Psychopathogica. Medical Publishing, London, UK.

2. Akalu YT, Gelaye AK, Bishaw AM, Tilahun YS, Yeshaw Y, et al. (2021) Depression, anxiety, and stress symptoms and its associated factors among residents of Gondar town during the early stage of COVID-19 pandemic. Risk Manag Healthc Policy 14: 1073-1083.

3. Uka V, Arifi A (2020) The link between Covid-19 virus and burnout in health professionals. European Journal of Education and Applied Psychology. Premier Publishing. Vienna, Austria.

4. Hidalgo RA, Pantaleon Y, Dios I, Falla D (2020) Fear of COVID-19, stress, and anxiety in university undergraduate students: A predictive model for depression.

5. Freudenberger HJ (1975) The staff burn-out syndrome in alternative institutions. Psychotherapy: Theory, Research \& Practice 12(1): 73-82.

6. Lovibond SH, Lovibond PF (1995) Manual for the depression, anxiety and stress scales. (2 ${ }^{\text {nd }}$ edn), Psychological Foundation, Sydney, Australia.

7. Lazarus RS (1990) Theory-based stress measurement. Psychol Inq 1: 3-13.

8. Maslach C, Jackson SE, Leiter MP (1996) MBI: The maslach burnout inventory: Manual. Consulting Psychologists Press, Palo Alto, USA.

9. Maslach C, Jackson SE (1981) The measurement of experienced burnout. Journal of Occupational Behavior 2(2): 99-113.

10. Spielberger CD (1983) Manual for the State-Trait Anxiety Inventory (STAI). Consulting Psychologists Press, Palo Alto, USA.

11. World Health Organization (2020) WHO director-general's opening remarks at the media briefing on COVID-19.

12. World Health Organization (2020) Rolling updates on coronavirus disease (COVID-19). 